ASIMTOT: JURNAL KEPENDIDIKAN MATEMATIKA

Volume 1 Nomor 1, Januari - Mei 2019, halaman 69 - 76

Tersedia Daring pada https://journal.unwira.ac.id/index.php/Asimtot

\title{
PENGARUH EFIKASI DIRI DAN DUKUNGAN SOSIAL GURU TERHADAP PRESTASI BELAJAR MATEMATIKA SISWA
}

\section{THE EFFECT OF SELF EFICATION AND TEACHER'S SOCIAL SUPPORT TO STUDENT MATHEMATICS ACHIEVEMENT}

\author{
Apolonia Letekina Uran, Samuel Igo Leton, Irmina Veronika Uskono \\ Program Studi Pendidikan Matematika UNWIRA \\ niauran2@gmail.com, letonsamel@gmail.com,veni_uskono@yahoo.com
}

\begin{abstract}
Abstrak: Penelitian ini bertujuan untuk mengetahui pengaruh efikasi diri dan dukungan sosial guru terhadap prestasi belajar matematika siswa kelas VII salah satu SMP Swasta di kota Kupang materi aritmetika sosial. Jenis penelitian yang digunakan yaitu kuantitatif dengan analisis statistik yang digunakan dalam penelitian ini yaitu analisis regresi berganda.Sampel dalam penelitian ini kelas VII A yang berjumlah 25 orang yang dipilih secara acak dari 4 kelas yang ada. Jenis data dalam penelitan ini yaitu data primer dengan pengumpulan data yang digunakan yaitu angket dan soal tes prestasi. Teknis analisis data dalam penelitian ini menggunakan analisis regresi ganda. Berdasarkan hasil uji secara parsial pada efikasi diri menunjukan bahwa $t_{\text {hitung }}=$ $3,164>1,71=t_{\text {tabel }}$, dukungan sosial guru diperoleh $t_{\text {hitung }}=2,954>1,71=t_{\text {tabel }}$, maka dengan taraf signifikan 5\% terdapat pengaruh secara parsial pada efikasi diri dan dukungan sosial guru. Selanjutnya, pada uji secara simultan menunjukan bahwa $F_{\text {hitung }}=55,176$ dan $F_{\text {tabel }}=3,44$ pada taraf signifikan 5\% yang berarti bahwa $F_{\text {hitung }}=55,176>3,44=F_{\text {tabel }}$, maka terdapat pengaruh simultan pada efikasi diri dan dukungan sosial guru. Dengan demikan, disimpulkan bahwa ada pengaruh efikasi diri dan dukungan sosial guru terhadap prestasi belajar matematika siswa.
\end{abstract}

Kata Kunci: Efikasi Diri, Dukungan Sosial Guru, Prestasi Belajar Siswa

Abstract: This study aims to determine the effect of self-efficacy and teacher social support on mathematics learning achievement of class VII students of one of the Private SMP in Kupang city social arithmetic material. The type of research used is quantitative with the statistical analysis used in this study, namely multiple regression analysis. The sample in this study is class VII A, amounting to 25 people randomly selected from 4 existing classes. The type of data in this research is primary data with data collection used, namely questionnaires and achievement test questions. Technical data analysis in this study used multiple regression analysis. Based on the partial test results on self efficacy showed that $t_{\text {count }}=3.164>1.71=t_{\text {table }}$, teacher social support obtained $t_{\text {count }}=2.954>1.71=t_{\text {table, }}$, then with a significant level of $5 \%$ there is a partial effect on self-efficacy and social support teacher. Furthermore, the simultaneous test shows that $F_{\text {count }}=55,176$ and $F_{\text {table }}$ at a significant level of 5\% which means that $F_{\text {count }}=55,176>3,44=F_{\text {table, }}$, then there is a simultaneous influence on teacher self-efficacy and social support.. Thus, it was concluded that there was an effect of teacher self-efficacy and social support on students' mathematics learning achievement.

Keywords: article Self Efficacy, Teacher Social Support, Student Learning Achievement

Cara Sitasi: Apolonia, L.U., Samuel ,I,L,. \& Irmina, V.U. (2019). Pengaruh Efikasi Diri Dan Dukungan Sosial Guru Terhadap Prestasi Belajar Matematika Siswa, Asimtot: Jurnal Kependidikan Matematika, 1(1), 69 - 76 
Perkembangan suatu ilmu pengetahuan, budaya, dan teknologi dipengaruhi oleh kemajuan dari sistem pendidikan. Pendidikan memegang peranan penting dalam menyiapkan sumber daya manusia yang berkualitas. Pendidikan dapat diperoleh melalui pendidikan formal, informal dan non formal. Pendidikan informal dapat berlangsung dalam keluarga, pergaulan sehari-hari dalam pekerjaan, masyarakat dan organisasi. Pendidikan non formal terdiri atas lembaga khusus, lembaga pelatihan atau pusat kegiatan belajar masyarakat. Pendidikan formal terdiri atas pendidikan anak usia dini, pendidikan dasar, pendidikan menengah dan pendidikan tinggi yang diselenggarakan di sekolah-sekolah (Prasko, 2013).

Tujuan pembelajaran matematika pada jenjang pendidikan tersebut adalah untuk mempersiapkan siswa dalam menghadapi perubahan di kehidupan dan dunia yang terus berkembang, melalui latihan bertindak atas dasar pemikiran secara logis, rasional, kritis, cermat, jujur, efisien dan efektif (Muttaqin, 2009). Terkait dengan pembelajaran, untuk menciptakan siswa yang berkualitas dan berprestasi tinggi maka siswa harus memiliki prestasi yang baik.

Prestasi belajar merupakan hasil pengukuran terhadap siswa setelah mengikuti proses pembelajaran yang diukur dengan menggunakan instrumen tes atau instrumen yang relevan. Namun, prestasi belajar matematika masih menjadi suatu permasalahan yang sering dibicarakan baik oleh orang tua maupun pakar pendidikan matematika itu sendiri (Anandari, 2013).

Masalah umum dalam pendidikan matematika di Indonesia adalah rendahnya minat terhadap pelajaran tersebut yang kemudian berpengaruh pada rendahnya prestasi belajar siswa. Nuraeni berpendapat bahwa hal-hal yang menyebabkan matematika menjadi momok adalah karena matematika menekankan pada penghafalan rumus, kurang variasi dalam proses belajar sehingga ada rasa bosan yang dirasakan siswa pada pelajaran tersebut kemudian mengakibatkan kurangnya minat belajar terhadap matematika (Anandari, 2013). Ada beberapa faktor yang mempengaruhi prestasi belajar yaitu faktor internal, eksternal dan faktor dukungan sosial (Azwar, 2010). Salah satu faktor internal yaitu efikasi diri dan faktor dukungan sosial yang berasal dari guru (Yoenanto, 2017).

Efikasi diri dapat mengukur kepercayaan diri seseorang dalam penguasaan terhadap tantangan baru (Hartzel, 2013). Selain itu efikasi diri yang tinggi dapat meningkatkan kepercayaan seseorang untuk mencapai keberhasilan. Siswa yang efikasi dirinya rendah mungkin tidak mau berusaha belajar untuk menghadapi ujian karena ia menganggap bahwa belajar tidak dapat membantunya mengerjakan ujian. Efikasi diri siswa akan meningkat apabila ia dapat mengatur emosi dan pikirannya, ketika guru menggunakan struktur kelas yang efektif.

Selain itu, dukungan sosial merupakan salah satu faktor yang mungkin mengakibatkan tinggi rendahnya prestasi belajar matematika siswa. Dukungan sosial mengarah pada kenyamanan, perhatian, penghargaan atau bantuan yang diterima seseorang dari orang lain atau kelompok tertentu. Ketika siswa merasa mendapat dukungan secara emosional dari guru, mereka akan lebih terlibat dalam pekerjaan akademiknya, termasuk dengan meningkatnya usahanya. Siswa akan merasa dirinya mendapatkan fasilitas dan perhatian, dalam hal ini dukungan yang dimaksud di lingkungan sekolah berasal dari guru. Oleh karena itu, dukungan sosial guru dan efikasi 
diri mempunyai pengaruh besar terhadap proses belajar siswa sehingga mempengaruhi prestasi belajar matematika siswa di sekolah.

Berdasarkan hasil studi pendahuluan pada SMPK Sta. Maria Assumpta Kupang, prestasi belajar matematika siswa beragam. Ada beberapa siswa memiliki prestasi matematika rendah. Rendahnya prestasi belajar siswa karena memiliki minat yang rendah pada pelajaran matematika. Siswa masih mengganggap bahwa pelajaran matematika itu sulit dan menakutkan. Mereka tidak mampu untuk menyelesaikannya karena kurang rasa percaya diri dalam menyelesaikan sebelum mencoba sehingga tidak mencapai kriteria ketuntasan minimal (KKM) yaitu 69 dalam ujian akhir semester. Adapun siswa yang memiliki prestasi matematika tinggi karena adanya rasa percaya diri siswa dalam menyelesaikan sebelum mencoba. Selain itu, guru yang telah memberi dukungan (mengayomi dan mengenal masing-masing karakter siswa). Efikasi diri siswa yang tinggi serta dukungan sosial guru yang memadai dapat membantu siswa dalam menyelesaikan masalah pembelajaran sehingga mencapai prestasi belajar yang tinggi.

Berdasarkan uraian di atas, maka peneliti ingin mengungkapkan pengaruh efikasi diri dan dukungan sosial guru terhadap prestasi belajar matematika. Sehingga peneliti melakukan suatu kajian ilmiah dengan judul "Pengaruh Efikasi Diri dan Dukungan Sosial Guru Terhadap Prestasi Belajar Matematika Siswa SMPK Sta. Maria Assumpta Kupang”.

\section{Metode Penelitian}

Jenis penelitian adalah penelitian kuantitatif dengan analisis yang digunakan yaitu analisis regresi berganda.
Penelitian ini dilakukan di kelas VII SMPK Sta. Maria Assumpta Kupang tahun ajaran 2018/2019. Sampel yang digunakan dalam penelitian ini yaitu satu kelas yang berjumlah 25 siswa dipilih secara random dari 4 kelas yang ada. Data dalam penelitian ini yaitu data primer untuk melihat prestasi belajar matematika siswa yang diambil secara langsung oleh peneliti di tempat penelitian.

Teknik pengumpulan data yang digunakan dalam penelitian ini berupa tes. Tes dilaksanakan berbentuk uraian dengan jumlah soal 5 nomor. Tes ini digunakan untuk melihat kemampuan pemecahan masalah matematis.

Instrumen tes dianalisis melalui empat langkah pengujian yaitu uji normalitas angket dan uji normalitas posttest, uji linearitas, uji multikolinearitas dan analisis regresi berganda.

\section{Hasil Penelitian dan Pembahasan}

\section{Hasil}

Uji Asumsi Klasik

Untuk menguji kebenaran hipotesis penelitian, analisis data didahului dengan uji asumsi klasik yang terdiri dari uji normalitas, uji linearitas, dan uji multikolinearitas.

\section{Uji Normalitas}

Pengujian normalitas data dilakukan menggunakan uji one simple KolmgorovSmirnov test. Adapun kriteria pengujiannya, yaitu dengan membandingkan nilai $\mathrm{D}_{\text {hitung }}$ dan $\mathrm{D}_{\text {tabel }}$ pada taraf signifikansi $5 \%$ yaitu: Jika $D_{\text {hitung }} \leq D_{\text {tabel }}$ maka terima $H_{0}$ artinya data berdistribusi normal

Jika $D_{\text {hitung }}>D_{\text {tabel }}$ maka tolak $H_{0}$ artinya data tidak berdistribusi normal

Hipotesis yang digunakan dalam pengujian ini ,yaitu : 
$\mathrm{H}_{0}$ : Data berdistribusi normal

$\mathrm{H}_{\mathrm{a}}$ : Data tidak berdistribusi normal

Tabel 1. Uji normalitas data angket dan posttest

\begin{tabular}{llll}
\hline Variabel & $\begin{array}{l}\text { Tes } \\
\text { Statistic }\end{array}$ & $\begin{array}{l}\text { Asymp. } \\
\text { Sig. (2- } \\
\text { tailed) }\end{array}$ & Keterangan \\
\hline Efikasidiri & 0,103 & 0,200 & $\begin{array}{l}\text { Berdistribusi } \\
\text { normal }\end{array}$ \\
\hline $\begin{array}{l}\text { Dukungan } \\
\text { sosial } \\
\text { guru }\end{array}$ & 0,150 & 0,150 & $\begin{array}{l}\text { Berdistribusi } \\
\text { normal }\end{array}$ \\
\hline $\begin{array}{l}\text { Prestasi } \\
\text { belajar }\end{array}$ & 0,168 & 0,067 & $\begin{array}{l}\text { Berdistribusi } \\
\text { normal }\end{array}$ \\
\hline
\end{tabular}

Berdasarkan hasil analisis uji normalitas untuk variabel $\mathrm{X}_{1}$ (Efikasi diri siswa) dengan $\alpha=0,05$ dan $\mathrm{N}=25$ pada output SPSS 22.0 for windows diperoleh nilai signifikansi $=0,200>0,05=\alpha$.

Karena

$D_{\text {hitung }}=0,103<0,275=$ $\mathrm{D}_{\text {tabel }}$, maka $\mathrm{H}_{0}$ diterima yang berarti data efikasi diri siswa berdistribusi normal.

Berdasarkan hasil analisis uji normalitas untuk variabel $\mathrm{X}_{2}$ ( Dukungan sosial guru ) dengan $\alpha=0,05$ dan $\mathrm{N}=$ 25 pada output SPSS 22.0 for windows diperoleh nilai signifikan $=0,150>$ $0,05=\alpha . \quad$ Karena $\quad D_{\text {hitung }}=0,150<$ $0,275=\mathrm{D}_{\text {tabel}}$, maka $H_{0}$ diterima yang berarti data dukungan sosial guru berdistribusi normal.

Berdasarkan hasil analisis uji normalitas untuk variabel Y (prestasi belajar matematika) dengan $\alpha=0,05$ dan $\mathrm{N}=$ 25 pada output SPSS 22.0 for windows diperoleh nilai signifikan $=0,067>$ $0,05=\alpha . \quad$ Karena $\quad D_{\text {hitung }}=0,168<$ $0,275=\mathrm{D}_{\text {tabel }}$, maka $\mathrm{H}_{0}$ diterima yang berarti data prestasi belajar berdistribusi normal.
Uji Linearitas

Adapun kriteria pengujiannya, yaitu dengan membandingkan nilai $\mathrm{F}_{\text {hitung }}$ dan $\mathrm{F}_{\text {tabel }}$ pada taraf signifikansi $5 \%$ yaitu :

Jika $F_{\text {hitung }} \leq F_{\text {tabel }}$ maka terima $H_{0}$ artinya data berpola linear

Jika $F_{\text {hitung }}>F_{\text {tabel }}$ maka tolak $H_{0}$ artinya data berpola tidak linear

Hipotesis yang digunakan dalam pengujian ini ,yaitu :

$\mathrm{H}_{0}$ : Data berpola linear

$\mathrm{H}_{\mathrm{a}}$ : Data tidak berpola linear

Tabel 2. Uji linearitas

\begin{tabular}{lcccc}
\hline Variabel & \multicolumn{3}{c}{ Sig. } & Keterangan \\
$\mathrm{X}$ & & & & \\
Terhadap & $F_{\text {hitung }}$ & $\mathrm{F}_{\text {tabel }}$ & & \\
$\mathrm{Y}$ & & & & \\
\hline $\mathrm{X}_{1}$ & & & 0,576 & Linear \\
terhadap & 0,923 & 3,22 & & \\
$\mathrm{Y}$ & & & & \\
\hline $\mathrm{X}_{2}$ & & & & Linear \\
$\begin{array}{l}\text { Terhadap } \\
\mathrm{Y}\end{array}$ & 0,923 & 2,72 & 0,096 & \\
& & & & \\
& & & &
\end{tabular}

Berdasarkan hasil analisis uji linearitas variabel $\mathrm{X}_{1}$ terhadap $\mathrm{Y}$ pada output SPSS 22 for windows, diperoleh nilai signifikansi pada Deviation for Linearity $=0,576>$ $0,05=\alpha$. dan diperoleh nilai $F_{\text {hitung }}=$ 0,923, $\alpha=0,05, d f_{1}=15$ dan $\quad d f_{2}=8$, diperoleh $\quad F_{\text {tabel }}=3,22$. Karena nilai signifikansi $=0,576>0,05=\alpha$, dan $F_{\text {hitung }}=0,923<3,22=F_{\text {tabel }}, \quad$ maka terima $\mathrm{H}_{0}$ yang berarti bahwa antara variabel $\mathrm{X}_{1}$ dan $\mathrm{Y}$ terdapat hubungan yang linear.

Berdasarkan hasil analisis uji linearitas variabel $\mathrm{X}_{2}$ terhadap $\mathrm{Y}$ pada output SPSS 22 for windows, diperoleh nilai signifikansi

pada 
Deviation for Linearity $=0,096>$

$0,05=\alpha$ dan diperoleh nilai $F_{\text {hitung }}=$ 2,198, $\alpha=0,05, d f_{1}=11$ dan $\quad d f_{2}=12$ diperoleh $\quad F_{\text {tabel }}=2,72$. Karena nilai signifikansi $=0,096>0,05=\alpha$, dan $F_{\text {hitung }}=2,198<2,72=F_{\text {tabel }}, \quad$ maka terima $\mathrm{H}_{0}$ yang berarti bahwa antara variabel $\mathrm{X}_{2}$ dan $\mathrm{Y}$ terdapat hubungan yang linear.

\section{Uji Multikolinearitas}

Uji multikolinieritas pada SSPS 22.0 for windows menggunakan korelasi Pearson dan pada analisis statistik manual menggunakan rumus:

$\mathrm{X}_{1} \mathrm{X}_{2}=\frac{n\left(\sum X_{1} X_{2}\right)-\left(\sum X_{1}\right) \cdot\left(\sum X_{2}\right)}{\sqrt{\left\{n \cdot \sum X 1^{2}-\left(\sum X 1\right)^{2}\right\} \cdot\left\{n \cdot \sum X 2^{2}-\left(\sum X 2\right)^{2}\right\}}}$

Berdasarkan hasil analisis pada output SSPS 22.0 for windows diperoleh nilai $V I F=3,220<10$ (Lampiran 18), Sehingga dapat disimpulkan bahwa tidak terdapat multikolinearitas antara variabel bebas (variabel $\mathrm{X}_{1}$ dan $\mathrm{X}_{2}$ ) dalam penelitian ini.

\section{Analisis Regresi Berganda}

Pengujian regresi ganda dan parsial dilakukan dengan menggunakan program SSPS 22.0 for windows. Berdasarkan tabel Anova diperoleh nilai $F_{\text {hitung }}=55,176$ dengan nilai signifikansi sebesar 0,001. Karena $\quad F_{\text {hitung }}=55,176>3,44=F_{\text {tabel }}$, dan nilai signifikansi $0,001<0,05$ maka dapat disimpulkan bahwa ada pengaruh secara bersama-sama dari variabel $X_{1}$ dan $X_{2}$ terhadap Y.

Selanjutnya dari tabel Coefficients didapat nilai a (konstanta) $=-9,212$ dan $b_{1}$ (koefisien regresi $\mathrm{X}_{1}$ ) $=$

$0,605, \quad b_{2}\left(\right.$ koefisien regresi $\left.X_{2}\right)=0,556$ sehingga persamaan regresi antara $X_{1}, X_{2}$, dan Y sebagai berikut:

$\widehat{Y}=\mathrm{a}+b_{1} X_{1}+b_{2} X_{2}$
$Y=-9,212+0,605 X_{1}+0,556 X_{2}$

Berdasarkan tabel Coefficients dapat dilanjutkan dengan uji regresi parsial membandingkan $t_{\text {hitung }}$ dan $t_{\text {tabel }}$. Pada kolom efikasi diri (lihat lampiran 19) diperoleh nilai $t_{\text {hitung }}=3,164$ dengan nilai signifikansi 0,004 karena $t_{\text {hitung }}=3,164>$ $1,71=t_{\text {tabel }}$ dan nilai signifikansi $0,004<$ 0,05 maka dapat disimpulkan bahwa ada pengaruh parsial dari variabel $\mathrm{X}_{1}$ (efikasi diri) terhadap variabel $\mathrm{Y}$ (prestasi belajar matematika).

Pada kolom dukungan sosial guru (lihat lampiran 19) diperoleh nilai $t_{\text {hitung }}=$ 2,954 dengan nilai signifikansi 0,007 karena $t_{\text {hitung }}=2,954>1,71=t_{\text {tabel }}$ dan nilai signifikansi $0,007<0,05$ maka dapat disimpulkan bahwa ada pengaruh parsial dari variabel $\mathrm{X}_{2}$ (dukungan sosial guru) terhadap variabel Y (prestasi belajar matematika).

\section{Pembahasan}

Efikasi diri merupakan keyakinan yang dimiliki oleh setiap siswa akan kemampuan yang dimilikinya untuk melakukan suatu tindakan ataupun tugas dengan suatu tujuan yang ingin dicapai. Siswa lebih mungkin terlibat dalam perilaku tertentu ketika mereka yakin bahwa mereka akan mampu menjalankan perilaku tersebut dengan sukses (Bandura, 2015). Efikasi diri mencakup beberapa aspek yaitu : (1) Tingkat Kesulitan Tugas (Magnitude); (2) Kekuatan Keyakinan (Strength); (3) Generalitas (Generality).

Dukungan sosial guru merupakan pertolongan atau bantuan yang diterima siswa ketika berinteraksi dengan guru yang berupa informasi, perhatian, emosi, penilaian dan bantuan instrumental yang membuat seseorang atau individu merasa diperhatikan, 
dicintai, dihargai dan menjadi bagian dari kelompok (Haris, 2008). Dukungan sosial guru mencakup beberapa aspek yaitu : (1) kepemimpinan (leadership); membantu/bersahabat (helping/friendly); (3) memahami (understanding); (4) tanggung jawab/kebebasan siswa (student responsibility/freedom);(5) ragu-ragu (uncertain);. (6) tidak puas (dissatisfied); (7) menjengkelkan (admonishing); (Lahey, 2010).

Efikasi diri dan dukungan sosial guru sangat berperan penting dalam tecapainya suatu prestasi belajar. Siswa dengan level efikasi diri rendah akan menghindari banyak tugas khususnya yang menantang dan sulit, sedangkan siswa yang memiliki level efikasi diri tinggi akan tekun berusaha untuk menguasai tugas pembelajaran tersebut. Guru dapat memotivasi dan meningkatkan hasil afektif dan kognitif siswa melalui dukungan guru yang lebih positif.

Pada penelitian ini diperoleh bahwa efikasi diri dan dukungan sosial guru berpengaruh secara signifikan pada prestasi belajar matematika siswa SMP kelas VII SMPK Sta. Maria Assumpta Kupang. Sebelum dilakukan tes prestasi, siswa terlebih dahulu diberi angket dengan sejumlah butir pernyataan untuk mengukur efikasi diri dan dukungan guru. Setelah angket diisi, kemudian diberi soal untuk mengukur prestasi belajar siswa. Setelah dianalisis nilai prestasi dikelompokkan berdasarkan kelompok unggul dan asor (terlampir). Jika prestasi belajar terkonstruksi dengan baik, efikasi diri siswa dan dukungan sosial guru juga akan terkonstruksi dengan baik.

Berdasarkan hasil analisis angket efikasi diri siswa diperoleh aspek yang paling tinggi dicapai siswa yaitu tingkat kesulitan tugas dengan persentase $58,77 \%$ (terlampir).
Siswa yang menjadi sampel mengerjakan soal yang mudah dahulu sesuai dengan kemampuan yang dimiliki serta pantang menyerah dalam menyelesaikan soal yang sulit.

Pencapaian aspek kekuatan keyakinan yaitu 55,94 \% (terlampir). Ada beberapa siswa memiliki efikasi diri tinggi dalam kerja keras atau usaha maksimal,tetap bertahan pada situasi yang sulit, optimisme, dan menambah waktu belajar sehingga mendorong untuk gigih dalam berupaya mencapai prestasi yang baik (Bandura, 2015). Pencapaian aspek generalitas yaitu 50,85\% (terlampir). Beberapa siswa pengharapan yang kuat dan mantap mendorong untuk gigih dalam berupaya mengerjakan soal walaupun mungkin belum sedangkan siswa lainnya cepat menyerah sehingga prestasi yang diperoleh pun belum maksimal.

Berdasarkan hasil analisis angket dukungan sosial guru diperoleh aspek yang paling tinggi dicapai siswa yaitu kepemimpinan dengan persentase $87,38 \%$ (terlampir). Guru berhasil memimpin kelas, mengorganisir, memberi perintah, menentukan prosedur dan memegang perhatian siswa sehingga belajar siswa lebih terarah dan prestasi sangat baik.

Pencapaian

aspek membantu/bersahabat yaitu $75,12 \%$. Pencapaian aspek memahami yaitu 76,27\%. Pencapaian aspek tanggung jawab/kebebasan siswa yaitu $75,09 \%$. Pencapaian aspek raguragu yaitu $67,93 \%$. Pencapaian aspek tidak puas yaitu $68 \%$. Sedangkan aspek dari angket dukungan sosial guru yang paling rendah dicapai siswa yaitu perilaku menjengkelkan dengan persentase $57,73 \%$ (terlampir). Guru sering menunjukkan kemarahan/ketidaksabarannya di kelas yang membuat beberapa siswa merasa tertekan 
sehingga belajar kurang terarah dan prestasi menurun.

Berdasarkan hasil analisis ouput SPSS 22.0 for windows ada pengaruh efikasi diri siswa terhadap prestasi belajar matematika pokok bahasan aritmetika sosial pada siswa kelas VII SMPK Sta. Maria Assumpta Kupang tahun ajaran 2018/2019. Siswa yang memiliki efikasi diri yang tinggi, akan lebih semangat dalam mengikuti proses pembelajaran di kelas, sehingga mampu membuat siswa memiliki harapan yang besar untuk mendapatkan prestasi yang baik.

Berdasarkan hasil analisis dapat disimpulkan bahwa ada dukungan sosial guru terhadap prestasi belajar matematika pokok bahasan aritmetika sosial pada siswa kelas VII SMPK Sta. Maria Assumpta Kupang tahun ajaran 2018/2019. Dukungan sosial guru merupakan pertolongan atau bantuan yang diterima anak didik ketika berinteraksi dengan guru yang berupa informasi, perhatian, emosi, penilaian dan bantuan instrumental yang membuat seseorang atau individu merasa diperhatikan, dicintai, dihargai dan menjadi bagian dari kelompok (Haris, 2008)

Berdasarkan hasil analisis disimpulkan bahwa dengan uji normalitas, linearitas, multikolinearitas, dan regresi berganda dapat diketahui bahwa ada pengaruh efikasi diri siswa dan dukungan sosial guru terhadap prestasi belajar matematika pokok bahasan aritmetika sosial SMPK Sta. Maria Assumpta Kupang tahun ajaran 2018/2019. Dengan menggunakan hasil ouutpt SPPS 22,00 for windows, uji $\mathrm{F}$ atau uji simultan pada efikasi diri dan dukungan sosial guru mempunyai pengaruh terhadap prestasi belajar matematika.

Dengan menggunakan hasil ouutpt SPPS 22,00 for windows, uji t atau uji parsial efikasi diri siswa dan dukungan sosial guru mempunyai pengaruh terhadap prestasi belajar matematika.

\section{Simpulan dan Saran}

\section{Simpulan}

Berdasarkan hasil analisis data dan pembahasan disimpulkan bahwa terdapat pengaruh efikasi diri siswa dan dukungan sosial guru baik secara parsial maupun secara simultan terhadap prestasi belajar matematika siswa kelas VII SMPK Sta. Maria Assumpta Kupang materi aritmetika sosial

\section{Saran}

Adapun rekomendasi bahwa diharapkan dari pihak-pihak sekolah khususnya guru mata pelajaran matematika agar tidak sering menunjukkan kemarahan/ketidaksabarannya di kelas yang membuat beberapa siswa merasa tertekan sehingga belajar kurang terarah dan prestasi menurun; memberikan informasi, perhatian, emosi, penilaian dan bantuan instrumental yang membuat siswa merasa diperhatikan, dicintai, dihargai dan menjadi bagian dari kelompok sehinnga tercapainya proses pembelajaran yang baik dan siswa mampu mencapai harapan dan cita-cita. Diharapkan kepada siswa agar memiliki keyakinan atau efikasi diri yang tinggi sehingga dapat meningkatkan prestasi belajar dan memiliki semangat yang tinggi serta lebih bersungguhsungguh dalam belajar.

\section{Daftar Pustaka}

Anandari, D. S. (2013). Hubungan Persepsi Siswa atas Dukungan Sosial Guru. 
Jurnal Psikologi Pendidikan dan Perkembangan , 212.

Azwar, S. (2010). pengantar psikologi intelgensi. Yogyakarta: Pustaka Pelajar.

Bandura, A. (2015, Juli 23). Hubungan Antara Self Efficacy Dengan Prestasi Belajar. Dipetik maret 9, 2019, dari skripsi Mulafi: http:/www.mulafiskripsipdf.com

Haris, B. (2008). Persepsi Self Eficacy dan Prestasi Belajar Siswa.

Hartzel. (2013). Hubungan Self Eficacy dengan Prestasi Belajar Siswa. Jurnal Perkembangan Psikologi .

Jumiati, Sari, M., \& Akmalia, D. (2011). Peningkatan Hasil Belajar Siswa dengan Menggunakan Model Numbereds Heads Together (NHT) pada Materi Gerak Tumbuhan di Kelas VIII SMP Sei Putih Kampar. 02.

Lahey. (2010). jurnal psikologi . Dukungan Sosial Guru dan Sesama. Dipetik maret 2, 2019, dari wordpress.com: https://www.google.com/amp/s/dukung an-sosial-guru-dan-sesama.html? $\mathrm{m}=1$

Muttaqin, H. (2009, juni minggu). tujuan pembelajaran matematika. Dipetik february 26, 2019, dari wordpress.com:https://www.google.co $\mathrm{m} / \mathrm{amp} / \mathrm{s} /$ muttaqinhasyim.wordpress.co m/2009/06/14/tujuan-pembelajaranmatematika/amp/

Prasko, a. (2013, february 7). macam-macam pendidikan. Dipetik maret 2, 2019, dari prasko17.blogspot.com:

prasko17.blogspot.com/2013/02/macam -macam-pendidikan-danjenjang.html?m=1.

Sukardi. (2012). Metodologi Penelitian Pendidikan. Jakarta: Bumi Aksara.
Yoenanto, N. h. (2017, Agustus). Pengaruh efikasi diri dan dukungan sosial guru terhadap prestasi belajar matematika pada siswa SMP di Surabaya. Prosiding Temu Ilmiah $X$ Ikatan Psikologi Perkembangan Indonesia , 90. 